\title{
Applicability of Health Informatics to Medical Practice - A Short Commentary
}

\author{
Paraskevi Pericleous* \\ Health eResearch Center, School of Health Sciences, Faculty of Biology, Medicine and Health, The University of Manchester, \\ Manchester, United Kingdom
}

\author{
Correspondence to: \\ Dr. Paraskevi Pericleous \\ Health eResearch Center, School of Health Sciences, Faculty of \\ Biology, Medicine and Health, The University of Manchester, \\ Manchester, United Kingdom \\ E-mail: paraskevi.pericleous@manchester.ac.uk
}

\section{EJBI 2018; 14(4):61-62}

Received: April 30, 2018

Accepted: September 15, 2018

Published: September 22, 2018

Health Informatics is the multidisciplinary field that tries to systems use this in practice or are in the process/discussion to improve healthcare systems and the patient's life. It is a term used use it?

extensively the latest years for topics related to health services [1]. From the latest technology, design for Randomized Control Trials (RCTs) or observational studies and data analysis tools (medical research, technology, statistical methodology, data mining, machine learning etc.).

Health Informatics has improved medical practice throughout the years e.g. clinicians can now find patient data more easily using the latest information retrieval techniques [1], physician's performance has been improved when computer-assisted prescribing is used [2], automating and extending the following time of pragmatic trials [1]. Medical research is usually trying to obtain more information about treatments/diseases in the form of RCTs, observational studies, cross-sectional etc. Statistical methodology is being extended and becoming more complicated by the year to support the needs for more medical research. New software and interventions are assessed quite often. All these are used to explain the underlying disease or treatment mechanisms, the effect of new interventions and other important topics. When you search different databases you can find numerous studies about everything you can think off that affects patients, from medical to statistical and technology research.

Nowadays, we are still working on the debate of RCTs versus pragmatic trials and how pragmatic a pragmatic trial can be [3]. However, we feel that there is one topic that is not given the attention that it deserves. We need all these outcomes/ conclusions/interventions to be part of the medical practice. Not many studies will end up being part of clinical practice $[4,5]$ and even less studies will be sustainable [5]. There is an urgent need for all this research to go into practice to make a difference and the procedure needs to be more efficient and more effective. For example, there have been several studies on using monitors to track physical activity in COPD patients as an educational and motivational tool $[6,7]$. Yet, again how many national healthcare
A study that assessed the path of new clinical technologies' applicability to the National Healthcare System (NHS) found that the Department of Health and National Institute for Health and Care Excellence (NICE) did not set any strict rules or guidelines for either using those or not and that key positions from nonspecialist clinicians affected the decision largely [8]. Some of the barriers that do not allow Health Informatics to be used in medical practice are: the cost of using the latest technology and staying up-to-date with it, the constant staff training to be able to use the technology and the lack of highly specialized people in decision-making positions [8].

Even though some investigators have tried to close the gap between research and practice $[4,5]$, the interest does not seem to shift more towards that direction. What should matter the most is not the results of a study, but on using the results of the study (beyond pilot-phase) to improve the patients' life. In order to succeed that, policy makers, researchers and practitioners need to shift their interest more into the patient's interest and health by applying all these new methods into healthcare. In order to succeed that, we need to change the process/attitude of the policy makers and national healthcare's leadership. More efficient and more effective guidelines and leadership is required e.g. having highly specialized people in decision-making positions, setting strict rules or guidelines on utilizing technology for best practice.

Additionally, Health Informatics should not rely in unscientific approaches [9]. There is a need to move from the traditional Health Informatics to Evidence-based Health Informatics (EBHI) [9]. The traditional approach includes using expert advice and untested theory with user requirements hoping that this could possibly benefit the users [9]. This can be changed into using expert advice or untested theory to evaluate studies, gather evidence and along with user requirements to create an EBHI system with predictable user benefits, such as having a faster and 
more efficient healthcare and having systems that fit with the clinical workflows [9].

Further studies are needed for assessing new technologies/ methods/treatments, how to identify the most important ones [9, 10], and how to improve an EBHI that would benefit the users/ patients [9]. There is also a need for further studies that improve the peer review process for the research funding proposals so that it would be directed to feasible, yet important and innovative studies [11]. However, this does not stop there. Applying EBHI specific interventions to Medical Practice needs to go beyond pilot-phase. Medical practice needs to follow more 'strict' guidelines based on those evidence and needs to have highly specialized people in decision-making positions.

\section{References}

1. Sullivan F. What is health informatics? J Health Serv Res Policy. 2001; 6: 251-254.

2. Hunt DL, Haynes RB, Hanna SE, Smith K. Effects of computer-based clinical decision support systems on physician performance and patient outcomes. JAMA. 1998; 280: 1339-1346.

3. Dal-Ré R, Janiaud P, Ioannidis JPA. Real-world evidence: How pragmatic are randomized controlled trials labeled as pragmatic? BMC Medicine.2018; 16(1): 49.

4. Bero LA, Grilli R, Grimshaw JM, Harvey E, Oxman AD, Thomson MA. Closing the gap between research and practice: an overview of systematic reviews of interventions to promote the implementation of research findings. The Cochrane Effective Practice and Organization of Care Review Group. BMJ. 1998; 317(7156):465-468.
5. Feldstein AC, Glasgow RE. A practical, robust implementation and sustainability model (PRISM) for integrating research findings into practice. Jt Comm J Qual Patient Saf. 2008; 34(4):228-243.

6. Mendoza L, Horta P, Espinoza J, Aguilera M, Balmaceda N, Castro A, et al. Pedometers to enhance physical activity in COPD: a randomised controlled trial. Eur Respir J. 2015; 45(2):347-354.

7. Moy ML, Martinez CH, Kadri R, Roman P, Holleman RG, Kim HM, et al. Long-Term Effects of an Internet-Mediated Pedometer-Based Walking Program for Chronic Obstructive Pulmonary Disease: Randomized Controlled Trial. J Med Internet Res. 2016; 18(8): e215.

8. Llewellyn S, Procter R, Harvey G, Maniatopoulos G, Boyd A. Facilitating technology adoption in the NHS: Negotiating the organisational and policy context - a qualitative study. Health Serv Deliv Res. 2014. 2.23.

9. Wyatt JC. Evidence-based Health Informatics and the Scientific Development of the Field. Stud Health Technol Inform. 2016; 222: 14-24.

10. Murray E, Hekler EB, Andersson G, Collins LM, Doherty A, Hollis C, et al. Evaluating Digital Health Interventions: Key Questions and Approaches. Am J Prev Med. 2016; 51(5): 843-851.

11. Shepherd J, Frampton GK, Pickett K, Wyatt JC. Peer review of health research funding proposals: A systematic map and systematic review of innovations for effectiveness and efficiency. PLoS One. 2018; 11; 13(5): e0196914. 